\title{
Apparent Diffusivity Model for Concrete Containing Supplementary Cementitious Materials
}

\author{
by Kyle A. Riding, Michael D. A. Thomas, and Kevin J. Folliard
}

\begin{abstract}
Concrete's resistance to chloride diffusion is one of the primary factors governing the concrete structure service life and life-cycle costs. This paper presents a new model developed for estimating the apparent concrete diffusivity based on the mixture proportions, cementitious materials used, and concrete age. The model includes the effects of supplementary cementitious material types commonly found in other service life models such as fly ash, ground-granulated blast-furnace slag, and silica fume. Also included are ultra-fine fly ash and metakaolin, which were not available in previous service life models. For validation of the model, chloride profiles have been measured on concrete blocks exposed daily to seawater for 25 years at the Treat Island, ME concrete exposure site. Concrete mixtures tested as part of the validation dataset contained up to $80 \%$ ground-granulated blast-furnace slag, 25\% fly ash, or $20 \%$ silica fume, and were compared against the predicted values and are presented in this paper.
\end{abstract}

Keywords: diffusion; long-term performance; transport properties.

\section{INTRODUCTION}

Concrete structures are expected by owners and engineers to be durable, with many now specifying a 75- to 100-year service life. Chloride-induced reinforcing steel corrosion is by far the most common durability problem with reinforced concrete structures. To achieve this desired service life in a cost-effective manner, engineers need tools to estimate the relative benefits of different materials and corrosion-prevention strategies.

The reinforcing steel of concrete is protected from corrosion by a passive layer of $\gamma$-ferric hydroxide that is normally stable in the high-pH environment of concrete, but this layer can be broken down in the presence of chlorides. ${ }^{1} \mathrm{~A}$ critical chloride concentration, called the chloride threshold value, is needed around the steel to depassivate the protective layer and induce corrosion. ${ }^{2}$ The time to corrosion initiation can be considered as the time it takes for the chloride concentration at the reinforcing steel depth to reach the chloride threshold value. After corrosion initiates, the corrosion products will deposit in the concrete pores. The increased volume of the corrosion products will eventually cause the concrete to crack and spall.

Chlorides can come in contact with the concrete surface in marine environments, from deicer salt application, or saline groundwater. The chlorides will then enter the concrete through absorption, diffusion, electromigration, thermal migration, hydrostatic pressure, or a combination of these transport processes. ${ }^{3}$ For concrete continually exposed to water and chlorides such as in a marine environment, diffusion is the primary chloride transport mechanism. Lowdiffusivity concrete helps slow the ingress of chlorides that come in contact with the surface. Low-diffusivity concrete is created by making concrete with a low porosity, small pore size distribution, and discontinuous pore structure. The use of a low water-cementitious material ratio $(w / \mathrm{cm})$ concrete and supplementary cementing materials (SCMs) have long been used to achieve concrete with a low diffusivity and to protect the reinforcing steel. ${ }^{4,5}$

Measurement of the true chloride diffusion coefficient for concrete is difficult for several reasons. First, the diffusion coefficient for most materials is measured under steady-state conditions. With concrete, the diffusion is quite slow and is not normally measured in steady-state conditions. External voltage, however, can be applied to concrete to speed up the chloride migration. ${ }^{6}$ Next, when chlorides penetrate into concrete, some of the chlorides react with $\mathrm{C}_{3} \mathrm{~A}$ to form Friedel's salt or with $\mathrm{C}_{4} \mathrm{AF}$ to form calcium chloroferrite, while the remainder of the chlorides continue to diffuse into the concrete. ${ }^{7}$ Diffusion occurs through the liquid phase in the concrete pores, whereas with concrete, the total cross section is generally used in measurements. An apparent diffusion coefficient is generally used that indirectly accounts for these effects and can be measured using the bulk diffusion method outlined in ASTM C1556. ${ }^{8}$ In this method, the chloride concentration in concrete ponded with chlorides $\left(165 \mathrm{~g} / \mathrm{L}\left[0.062 \mathrm{lb} / \mathrm{ft}^{3}\right]\right)$ is measured. In this method, a pre-saturated concrete specimen is ponded in a chloride solution $\left(165 \mathrm{~g} / \mathrm{L}\left[0.062 \mathrm{lb} / \mathrm{ft}^{3}\right] \mathrm{NaCl}\right)$ for a period of time (minimum 35 days) and then a chloride concentration profile is established. The chloride ingress through the concrete in the ASTM C1556 test is a non-steady-state mass transport problem. The apparent chloride diffusion coefficient is determined by fitting a numerical solution of Fick's second law to the resulting concentration profile. The approach in ASTM C1556 assumes that the diffusion coefficient is constant with time; however, an iterative procedure has been proposed $^{9}$ to account for the reduction in the coefficient during the test, thereby yielding the instantaneous diffusion coefficient at the start of the test (typically 28 days).

Engineers need a tool for quantitatively comparing the relative performance of the different reinforcing steel corrosion prevention options. This paper documents the development of a new model for concretes exposed to chlorides, which includes a new model for estimating the diffusion based on the mixture proportions and cementitious materials used. This new model improves on the commonly used Life-365 model by using a more realistic equation for the decrease in the concrete's apparent chloride diffusivity with time. The new model builds on the data used in developing

ACI Materials Journal, V. 110, No. 6, November-December 2013

MS No. M-2012-194 received June 19, 2012, and reviewed under Institute publication policies. Copyright (C) 2013, American Concrete Institute. All rights reserved, including the making of copies unless permission is obtained from the copyright proprietors. Pertinent discussion including author's closure, if any, will be published in the September-October 2014 ACI Materials Journal if the discussion is received by June 1,2014 
ACI member Kyle A. Riding is an Assistant Professor in the Department of Civil Engineering at Kansas State University, Manhattan, KS. He received his MSE and PhD from The University of Texas at Austin, Austin, TX. He is the Secretary of ACI Committee 231, Properties of Concrete at Early Ages, and is a member of ACI Committees 201, Durability of Concrete; 236, Material Science of Concrete; and S803, Faculty Network. He received the Wason Medal for Materials Research in 2011.

Michael D. A. Thomas, FACI, is a Professor of civil engineering at the University of New Brunswick, Fredericton, NB, Canada. He is a member of ACI Committees 201, Durability of Concrete; 221, Aggregates; 232, Fly Ash and Natural Pozzolans in Concrete; 233, Ground Slag in Concrete; 234, Silica Fume in Concrete; 236, Material Science of Concrete; 308, Curing Concrete; 365, Service Life Prediction; and S803, Faculty Network.

Kevin J. Folliard, FACI, is a Professor in the Department of Civil, Architectural and Environmental Engineering at The University of Texas at Austin. He received his PhD in civil engineering from the University of California, Berkeley, Berkeley, CA, in 1995. He is a member of ACI Committees 201, Durability of Concrete, and 350, Environmental Engineering Concrete Structures. He received the ACI Young Member Award for Professional Achievement in 2002 and the Wason Medal for Materials Research in 2011.

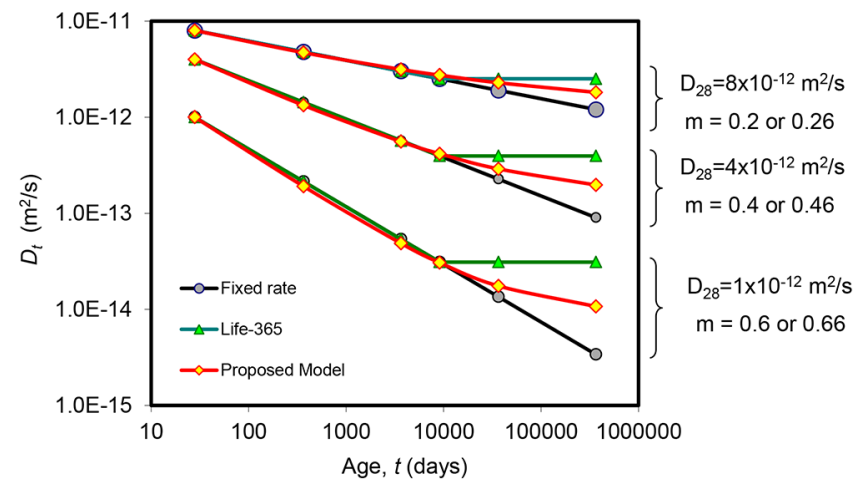

Fig. 1-Comparison of different approaches for accounting for time dependence of diffusion coefficient. (Note: $1 \mathrm{~m}^{2} / \mathrm{s}=$ $10.77 \mathrm{ft}^{2} / \mathrm{s}$.)

the equations for the Life-365 concrete 28-day apparent diffusion coefficient for concrete with different $w / \mathrm{cm}$ and for concrete containing silica fume. The model also includes equations for metakaolin and ultra-fine fly ash, which were not previously available in the Life-365 model. ${ }^{10}$ Validation of the service life model that incorporates the developed concrete diffusion model was performed using chloride profiles taken from concrete blocks stored at the Treat Island, ME field exposure site. The Treat Island, ME exposure site is subject to very high tides and more than 100 freezingand-thawing cycles per year. ${ }^{11}$ These blocks were made from concrete with various amounts of SCMs and subject to field exposure for periods of up to 25 years.

\section{RESEARCH SIGNIFICANCE}

Concrete chloride service life models are being used to help design mixtures for a long service life. A model for calculating the chloride concentration with time for concrete exposed to chlorides is presented. The model has been validated against field exposure blocks that have been exposed to seawater for 25 years. This validation illustrates the strengths of this model and areas of durability concern where caution should be used in developing mixtures.

\section{DIFFUSION MODEL DEVELOPMENT}

A number of researchers have shown that the relationship between diffusivity and time is best described by a power law, ${ }^{12-16}$ where the exponent is potentially a function of both the materials (for example, mixture proportions) and the environment (for example, temperature and humidity). Equation (1) is an example of such a relationship

$$
D_{t}=D_{28} \cdot\left(\frac{t_{28}}{t}\right)^{m}
$$

where $D_{t}$ is the concrete apparent diffusion coefficient $\left(\mathrm{m}^{2} / \mathrm{s}\right)$ at time $t$ (days); $D_{28}$ is the concrete apparent diffusion coefficient at time $t_{28}=28$ days; and $m$ is a (decay) constant.

Mangat and Molloy ${ }^{14}$ proposed a relationship between $m$ and the water-cement ratio $(w / c)$ of the concrete (that is, $m=2.5 w / \mathrm{cm}-0.6$ ). However, other researchers have shown the value of $m$ to be mainly influenced by the nature of the cementitious materials, particularly the presence of fly ash or ground-granulated blast-furnace slag (GGBFS), ${ }^{12,13,16}$ with the $w / c$ mainly influencing the initial diffusion coefficient $^{13}$ - that is, $D_{28}$ in Eq. (1).

It is difficult to imagine that the diffusivity will continue to decrease indefinitely, and one might expect that the diffusion coefficient decays to an ultimate limiting value, $D_{u l t}$. This can be readily accounted for in a mathematical model by adding this term to Eq. (1), which becomes Eq. (2), which was used in the service-life model

$$
D_{t}=D_{28} \cdot\left(\frac{t_{28}}{t}\right)^{m}+D_{u l t}\left(1-\left(\frac{t_{28}}{t}\right)^{m}\right)
$$

Of course, the determination of an appropriate value for $D_{u l t}$ is somewhat problematic. For this model, it was decided to use the 100-year value predicted by Eq. (3) for the value of $D_{u l t}$ as shown in Eq. (3)

$$
D_{u l t}=D_{28}\left(\frac{28}{36,500}\right)^{m}
$$

Figure 1 compares the proposed approach for this model with the approach adopted by Life-365 and that of allowing the diffusion coefficient to decrease indefinitely, as in Eq. (1). All three approaches result in essentially the same behavior up to 25 years. Beyond this period, Life-365 permits no further reduction, whereas allowing the concrete apparent diffusion coefficient to decrease according to Eq. (1) allows significant further reductions with time. It is argued that the approach proposed for the new model is intuitively more correct, allowing the diffusion coefficient to decay asymptotically to some ultimate value.

Algorithms were developed as part of this study to predict the impact of the mixture proportions $(w / \mathrm{cm})$ and binder type (level of supplementary cementing material) on the 28-day concrete apparent diffusion coefficient $D_{28}$ and the rate of decay of the diffusion coefficient as represented by decay coefficient $m$. Some of these algorithms were developed using the results of diffusion tests published in the literature and unpublished data from the University of New Brunswick (UNB). In the UNB tests, the procedure used was ASTM C1556 $6^{8}$; concrete samples were 28 days old at the time of immersion in $\mathrm{NaCl}$ solution and the chloride concentration profile was established after 35 days in solution at laboratory temperature. The UNB procedure was established 


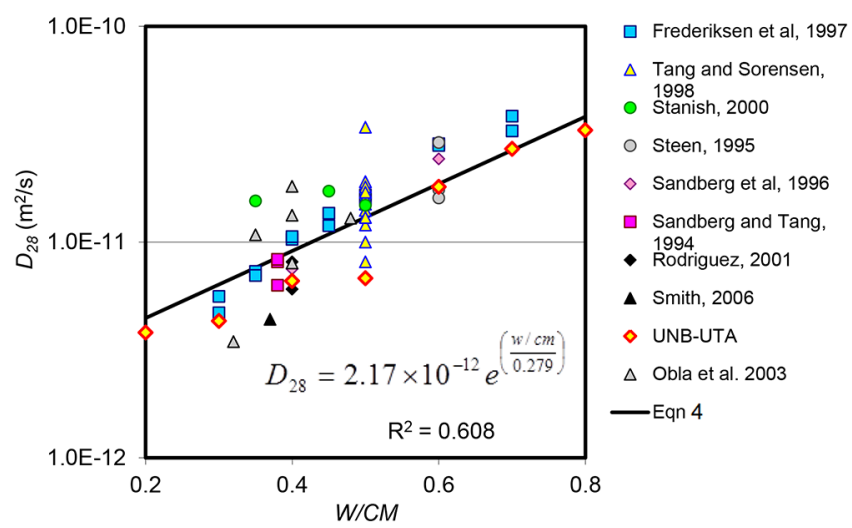

Fig. 2-Relationship between $\mathrm{D}_{28}$ and $\mathrm{w} / \mathrm{cm}$ : all data. (Note: $1 \mathrm{~m}^{2} / \mathrm{s}=10.77 \mathrm{ft}^{2} / \mathrm{s}$.)

to determine the diffusion coefficient as early as reasonably possible $(28$ days curing +35 days on chloride solution $=$ 63 days in total) and these tests were conducted specifically to provide input to the model. Data from these tests are designated as UNB-UTA (University of Texas at Austin). The published data were collected using the same type of test, although the age of specimens and exposure conditions varied between the different studies. The data found in the literature were collected using the same type of test but had a wide amount of scatter because of different temperature, duration of ponding, $\mathrm{C}_{3} \mathrm{~A}$ contents to bind chlorides, and method of chloride measurement from the chloride profile grinding samples.

\section{Effect of $w / \mathrm{cm}$ on $D_{28}$}

Figure 2 shows the relationship between the early-age diffusion coefficient $D_{28}$ and the $w / \mathrm{cm}$ from a number of studies. ${ }^{17-25}$ The seven UNB-UTA mixtures in this data set were produced with $w / \mathrm{cm}$ ranging from 0.20 to 0.80 (in 0.10 increments). These concrete mixtures contained between 225 to $725 \mathrm{~kg} / \mathrm{m}^{3}$ ( 379 to $1222 \mathrm{lb} / \mathrm{yd}^{3}$ ) of a Type I portland cement $\left(12 \% \mathrm{C}_{3} \mathrm{~A}\right)$. The main purpose in conducting these tests was to determine the best form of the equation for concretes produced with similar materials. There is a wide spread in these data and this attributed to the differences in materials used and probably the experimental procedures (for example, temperature, duration of ponding, method of chloride analysis). For the purposes of the service life model, the following "best-fit" equation was selected (Eq. (4))

$$
D_{28}=2.17 \times 10^{-12} e^{(w / c m) / 0.279}
$$

\section{Effect of silica fume on $D_{28}$}

Figure 3 shows the ratio of the diffusion coefficient of concrete with portland cement plus silica fume (SF) to that of concrete with portland cement only, $D_{S F} / D_{P C}$, plotted as a function of the silica fume content of the binder. ${ }^{19,21,24-30}$ The four UNB-UTA mixtures in this data set were produced with $w / \mathrm{cm}=0.40$ with silica fume contents ranging from $\mathrm{SF}=3 \%$ to $12 \%$ (in $3 \%$ increments). The published data used were limited to tests made on concrete that was no more than 6 months old. For the purposes of the service life model, a "best-fit" equation was selected and is shown in Eq. (5)

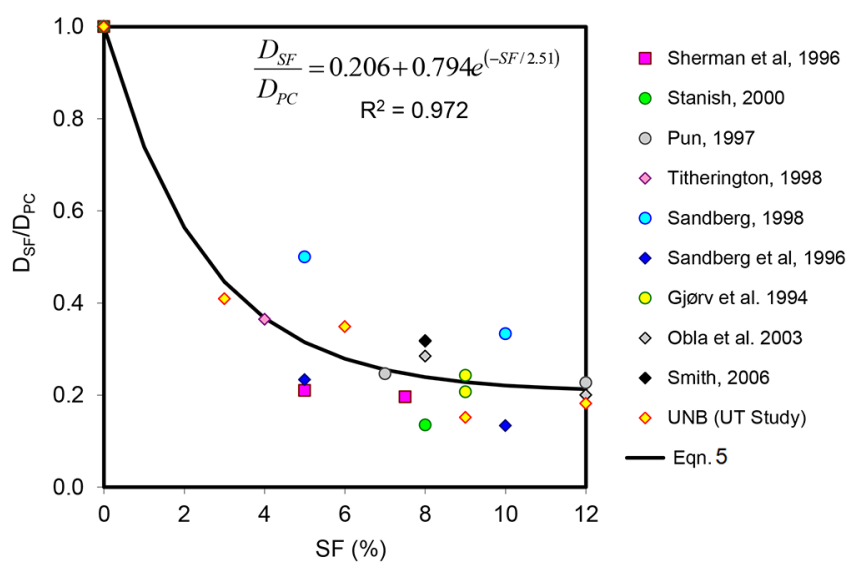

Fig. 3-Relationship between $\mathrm{D}_{\mathrm{SF}} / \mathrm{D}_{\mathrm{PC}}$ and SF: all data.

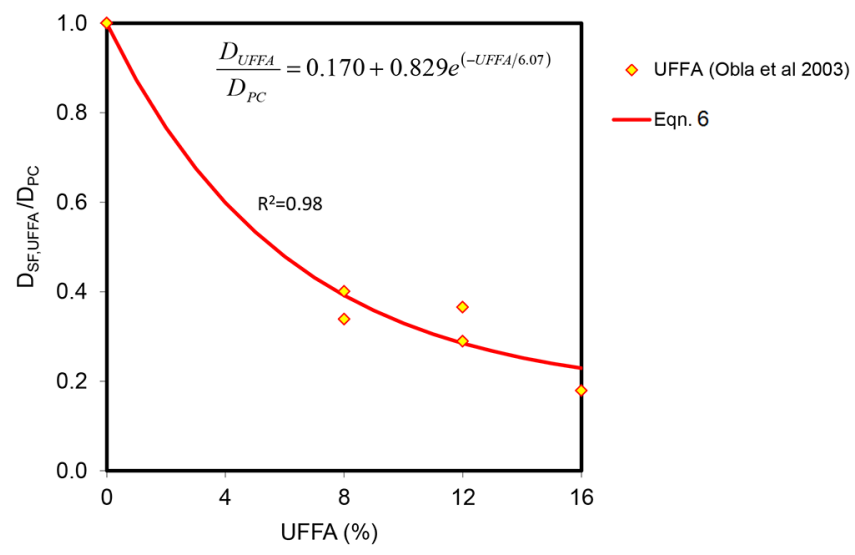

Fig. 4-Relationship between $\mathrm{D}_{\mathrm{UFFA}} / \mathrm{D}_{\mathrm{PC}}$ and percent UFFA. ${ }^{25}$

$$
\frac{D_{S F}}{D_{P C}}=0.206+0.794 e^{(-S F / 2.51)}
$$

\section{Effect of ultra-fine fly Ash on $D_{\mathbf{2 8}}$}

Figure 4 shows the ratio of the diffusion coefficient of concrete with portland cement plus ultra-fine fly ash (UFFA) to that of concrete with portland cement only, $D_{U F F A} / D_{P C}$, plotted as a function of the ultra-fine fly ash content of the binder. ${ }^{25}$ The ultra-fine fly ash used in these tests had an average particle size of 3 microns. The results shown are for concrete samples that were tested in accordance with ASTM $\mathrm{C} 1556^{8}$ at an age of 28 days with an immersion period of 40 days. ${ }^{25}$ For the purposes of the service life model, Eq. (6) was the "best-fit" equation and was selected

$$
\frac{D_{U F F A}}{D_{P C}}=0.170+0.829 e^{(-U F F A / 6.07)}
$$

\section{Effect of metakaolin on $D_{28}$}

Figure 5 shows the ratio of the diffusion coefficient of concrete with portland cement plus metakaolin $(M K)$ to that of concrete with portland cement only, $D_{M K} / D_{P C}$, plotted as a function of the metakaolin content of the binder. The results shown are for concrete samples that were tested in accordance with ASTM C1556 at an age of 28 days and the 


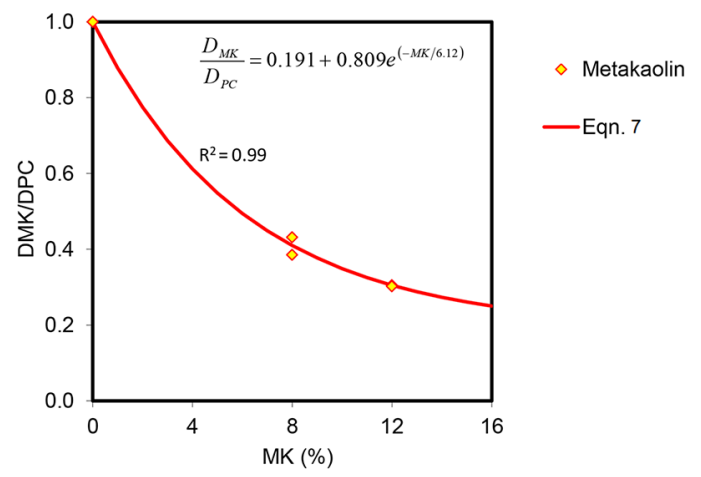

Fig. 5-Relationship between $\mathrm{D}_{\mathrm{MK}} / \mathrm{D}_{\mathrm{PC}}$ and percent $M K .^{3 l}$

immersion period was just 28 days. ${ }^{31}$ For the purposes of the service life model, the following "best-fit" equation was selected and shown in Eq. (7)

$$
\frac{D_{M K}}{D_{P C}}=0.191+0.809 e^{(-M K / 6.12)}
$$

\section{Time-dependent decay of diffusion coefficient and role of fly ash and slag}

Based on a review of published data, Bamforth ${ }^{32}$ proposed a value of $m=0.264$ for plain portland-cement concrete and values of 0.699 and 0.621 for concrete containing fly ash and slag, respectively. Bamforth made no distinction between concretes with varying levels of fly ash or slag. In the model Life- $365,{ }^{10}$ the value of $m$ varies between 0.2 for concrete without fly ash and slag, up to 0.6 for concrete with either $50 \%$ fly ash or $70 \%$ slag; the value changes linearly for intermediate levels of fly ash and slag. However, in the Life-365 software package, the diffusion coefficient only decreases until it reaches an age of 25 years, after which time it remains constant. The new service life model uses an approach somewhere between these two, where $m=0.26$ for concrete without fly ash and slag and increases linearly to $m=0.66$ as the fly ash content increases from zero to $50 \%$ or the slag from zero to $70 \%$. The resulting equation is shown in Eq. (8)

$$
m=0.26+0.4\left(\frac{F A}{50}+\frac{S G}{70}\right)
$$

where $F A$ is the fly ash content (class $\mathrm{F}$ fly ash or ultra-fine fly ash) as a percentage of the total cementitious material content by weight; and $S G$ is the slag cement content as a percentage of the total cementitious material content by weight. In this model, silica fume and metakaolin are assumed to have no effect on $m$.

\section{CHLORIDE EXPOSURE SERVICE LIFE MODELING}

Fick's second law of diffusion was used to model the chloride ingress with time, as shown in Eq. (9) 33

$$
\frac{\partial}{\partial x}\left(D_{c} \frac{\partial C}{\partial x}\right)+\frac{\partial}{\partial y}\left(D_{c} \frac{\partial C}{\partial y}\right)+\frac{\partial}{\partial z}\left(D_{c} \frac{\partial C}{\partial z}\right)=\frac{\partial C}{\partial t}
$$

where $D_{c}$ is the diffusion coefficient $\left(\mathrm{m}^{2} / \mathrm{s}\right) ; C$ is the chloride concentration (\%); and $t$ is time (s). Fick's second law of diffusion as shown assumes that the concrete is uncracked, saturated, has a constant density, and that diffusion is the only mass transport mechanism. A term could be added to Eq. (9) to account for chemical binding of the chlorides directly, although this would assume a linear relationship between the chloride concentration and binding, which may introduce additional error into the model. The chloride diffusion coefficient used, however, is an apparent diffusion coefficient that takes chloride binding into account indirectly, making the addition of a chemical binding term unnecessary. A comparison of the chloride profiles of field exposed concrete to predicted values using Fick's second law of diffusion will show the magnitude of errors caused by these assumptions. A finite difference control volume mass balance approach that used a fully explicit time stepping technique was used to solve Fick's law for the chloride concentration in the concrete with time. The software developed contains built-in models for one-dimensional (1-D) walls and bridge decks, two-dimensional (2-D) columns, and circular columns. The use of polar coordinates in modeling circular columns, along with the assumption that the chloride ingress was axisymmetrical, reduced the modeling for circular columns to a 1-D mass transfer problem.

Temperature can change the chloride diffusion rate by altering the rate of concrete densification from continued hydration and by altering the rate of the chloride ions diffusing through the concrete. The change in the concrete diffusivity from altered hydration rates from temperature is not included in this model because of a lack of longterm data. At higher temperatures, the chloride ions will randomly move at faster rates, increasing the diffusion rate. The converse is true at cold temperatures. This change in the chloride diffusion process with temperature is included in the model using an Arrhenius equation as shown in Eq. (10) that adjusts the concrete diffusion coefficient based on the temperature and activation energy

$$
D_{t T}(t, T)=D_{t}(t) \cdot \exp \left[\frac{U}{R} \cdot\left(\frac{1}{T_{r e f}}-\frac{1}{T}\right)\right]
$$

where $D_{t T}$ is the concrete diffusion coefficient $\left(\mathrm{m}^{2} / \mathrm{s}\right)$ at time $t$ for temperature $T(\mathrm{~K}) ; U$ is the activation energy $(\mathrm{J} / \mathrm{mol})$; $R$ is the universal gas constant $(8.3144 \mathrm{~J} / \mathrm{mol} / \mathrm{K}) ; T$ is the concrete temperature $(\mathrm{K})$ at time $t$; and $T_{r e f}$ is the reference temperature $(\mathrm{K})$. The yearly temperature profile used for the model was made from the average air temperature for the first day of each month calculated from the average 30-year hourly weather data from the National Climatic Data Center (NCDC), which is part of the National Oceanic and Atmospheric Administration. A linear interpolation is used for times between the first days of each month.

Fick's second law, as shown in Eq. (9), only models diffusion-related chloride ingress in the concrete and not the chloride penetration into the concrete at the surface. For concrete in a marine splash zone or completely immersed in seawater, the chloride concentration in the salt water is well known and can be enforced as the surface chloride concentration. For concrete exposure with wetting and drying or intermittent exposure to chlorides, the chloride surface concentration is modeled according to Eq. (11)

$$
C_{s}(t)=C_{s \max } \cdot \frac{b \cdot\left(t-t_{c e}\right)}{1+b \cdot\left(t-t_{c e}\right)}
$$


Table 1-Concrete block cementitious materials used and goodness of model fit

\begin{tabular}{|c|c|c|c|c|c|c|c|c|c|}
\hline Phase & Year made & $w / \mathrm{cm}$ & Block ID & GGBFS, $\%$ & Fly ash, $\%$ & Silica fume, $\%$ & No. data points & $R^{2}$ & AAE, $\%$ \\
\hline \multirow{10}{*}{ I } & \multirow{10}{*}{1978} & \multirow{4}{*}{0.4} & A5 & - & - & - & 9 & 0.90 & 0.07 \\
\hline & & & A3 & 25 & - & - & 8 & 0.76 & 0.08 \\
\hline & & & A7 & 45 & - & - & 10 & 0.96 & 0.03 \\
\hline & & & A11 & 65 & - & - & 9 & 0.95 & 0.03 \\
\hline & & \multirow{2}{*}{0.5} & B5 & - & - & - & 10 & 0.64 & 0.12 \\
\hline & & & B3 & 25 & - & - & 10 & 0.84 & 0.07 \\
\hline & & \multirow{4}{*}{0.6} & $\mathrm{C} 5$ & - & - & - & 10 & 0.75 & 0.10 \\
\hline & & & $\mathrm{C} 3$ & 25 & - & - & 10 & 0.66 & 0.13 \\
\hline & & & $\mathrm{C} 7$ & 45 & - & - & 10 & 0.73 & 0.08 \\
\hline & & & $\mathrm{C} 11$ & 65 & - & - & 9 & 0.67 & 0.09 \\
\hline \multirow{5}{*}{ II } & \multirow{5}{*}{1979} & 0.4 & D1 & - & 0 & - & 10 & 0.90 & 0.07 \\
\hline & & \multirow{4}{*}{0.5} & E1 & - & 0 & - & 10 & 0.79 & 0.11 \\
\hline & & & E2 & - & 25 & - & 10 & 0.86 & 0.06 \\
\hline & & & E6 & 40 & 20 & - & 10 & 0.72 & 0.07 \\
\hline & & & E10 & 60 & 20 & - & 10 & 0.62 & 0.08 \\
\hline \multirow{6}{*}{ III } & \multirow{6}{*}{1980} & \multirow{4}{*}{0.4} & - & - & - & - & 10 & 0.61 & 0.15 \\
\hline & & & - & 25 & - & - & 10 & 0.90 & 0.05 \\
\hline & & & - & 45 & - & - & 10 & 0.92 & 0.04 \\
\hline & & & - & 65 & - & - & 10 & 0.97 & 0.02 \\
\hline & & \multirow{2}{*}{0.5} & - & - & - & - & 10 & 0.86 & 0.09 \\
\hline & & & - & 25 & - & - & 10 & 0.92 & 0.05 \\
\hline IV & 1981 & 0.6 & $\mathrm{~K} 2$ & - & - & - & 10 & 0.71 & 0.14 \\
\hline \multirow{12}{*}{$\mathrm{V}(\mathrm{A})$} & & & M2-1 & - & - & - & 4 & 0.22 & 0.27 \\
\hline & & 0.4 & M2-2 & - & - & - & 5 & 0.26 & 0.25 \\
\hline & & & M4-1 & 80 & - & - & 5 & 0.94 & 0.05 \\
\hline & & & M4-2 & 80 & - & - & 5 & 0.90 & 0.06 \\
\hline & & & N2-1 & - & - & - & 5 & 0.57 & 0.13 \\
\hline & 1082 & 05 & $\mathrm{~N} 2-2$ & - & - & - & 5 & 0.40 & 0.20 \\
\hline & 1902 & 0.5 & N4-1 & 80 & - & - & 5 & 0.78 & 0.09 \\
\hline & & & N4-2 & 80 & - & - & 5 & 0.67 & 0.12 \\
\hline & & & $\mathrm{O} 2-1$ & - & - & - & 5 & 0.33 & 0.20 \\
\hline & & 06 & $\mathrm{O} 2-2$ & - & - & - & 5 & 0.19 & 0.28 \\
\hline & & 0.0 & O4-1 & 80 & - & - & 5 & 0.56 & 0.16 \\
\hline & & & $\mathrm{O} 4-2$ & 80 & - & - & 5 & 0.54 & 0.16 \\
\hline & & & Q1-1 & - & - & - & 5 & 0.33 & 0.19 \\
\hline & & & Q1-2 & - & - & - & 5 & 0.24 & 0.24 \\
\hline & & & Q2-1 & - & - & 10 & 5 & 0.62 & 0.13 \\
\hline $\mathrm{V}(\mathrm{B})$ & 1082 & 06 & Q2-2 & - & - & 10 & 5 & 0.52 & 0.16 \\
\hline$V(B)$ & 1982 & 0.6 & Q3-1 & - & - & 15 & 5 & 0.46 & 0.19 \\
\hline & & & Q3-2 & - & - & 15 & 5 & 0.50 & 0.17 \\
\hline & & & Q4-1 & - & - & 20 & 5 & 0.34 & 0.27 \\
\hline
\end{tabular}


Table 2-Chemical and physical properties of cements used in study ${ }^{38}$

\begin{tabular}{|c|c|c|c|c|c|c|}
\hline Property & Phase I & Phase II & Phase III & Phase IV & Phase V & Phase VI \\
\hline ASTM C150 cement type & $\mathrm{I}$ & $\mathrm{I}$ & $\mathrm{I}$ & $\mathrm{I}$ & $\mathrm{I}$ & II \\
\hline $\mathrm{SiO}_{2}, \%$ & 20.56 & 20.71 & 20.52 & 20.5 & 20.8 & 21.35 \\
\hline $\mathrm{CaO}$ (free), $\%$ & 0.53 & 0.56 & 0.63 & 0.59 & 0.9 & 0.63 \\
\hline Insoluble, \% & 0.47 & 0.53 & 0.46 & 0.39 & 0.3 & 0.41 \\
\hline $\mathrm{Fe}_{2} \mathrm{O}_{3}, \%$ & 1.99 & 2.03 & 2.1 & 2.68 & 2.5 & 3.11 \\
\hline $\mathrm{SO}_{3}, \%$ & 4.63 & 4.03 & 3.87 & 3.9 & 3.8 & 2.74 \\
\hline $\mathrm{MgO}, \%$ & 1.44 & 1.38 & 1.62 & 1.27 & 1.4 & 2.1 \\
\hline $\mathrm{Na}_{2} \mathrm{O}, \%$ & 0.08 & 0.11 & 0.08 & 0.26 & 0.25 & - \\
\hline $\mathrm{C}_{2} \mathrm{~S}, \%$ & 23.6 & 24.5 & 23.1 & 17 & 22 & 20.1 \\
\hline $\mathrm{C}_{3} \mathrm{~A}, \%$ & 11.4 & 11.8 & 12.6 & 8.5 & 9.3 & 6.1 \\
\hline $\mathrm{C}_{4} \mathrm{AF}, \%$ & 6.1 & 6.2 & 6.4 & 8.2 & 7.6 & 9.5 \\
\hline
\end{tabular}

where $C_{s}(t)(\%)$ is the chloride surface concentration with time $t$ (years); $C_{\text {smax }}$ is the maximum chloride surface concentration $(\%) ; b$ is the chloride surface concentration build-up rate constant; and $t_{c e}$ is the concrete age at first exposure to chlorides (years). The chloride concentration in the concrete with depth and time is very sensitive to the chloride surface concentration. The software contains default values for $C_{\text {smax }}$ and $b$ depending on the type of structure and geographical location; however, care should be exercised in interpreting these results because of different local deicer salt application rates and drainage.

The model developed uses a simplified corrosion damage model proposed by Tuutti, ${ }^{34}$ which assumes that the concrete damage propagation increases linearly with time after the chloride concentration at the reinforcing steel depth reaches its chloride threshold. A one-size-fits-all corrosion threshold value for determining the initiation of concrete damage from corrosion clearly is not accurate. The concrete temperature, relative humidity, mixture proportions, and SCMs and concrete and steel materials used will affect the chloride concentration at which corrosion begins. A model, however, does not exist to predict the chloride threshold for all of the previously mentioned conditions, nor will these variables always be known at design. A single chloride threshold value is simplistic, but provides a needed metric for comparing the relative fitness of different mixtures and chloride protection methods. For the model developed, a chloride threshold of $0.05 \%$ chloride by mass of concrete was used for black steel, and $0.5 \%$ chloride by mass concrete for Grade 316 stainless steel was used, as recommended by other researchers. ${ }^{10,35}$

\section{FIELD VALIDATION}

A study by the Canadian Centre for Mineral and Energy Technology (CANMET) was begun in 1978 to determine the long-term durability of concrete containing new or alternative concrete materials under harsh field exposure. ${ }^{36} \mathrm{~A}$ total of 16 phases examining the use of SCMs, fibers, different aggregate types, and steels were initiated. As part of the study, two 305 × 305 x 915 mm (12 x 12 x 36 in.) concrete blocks for each mixture were placed on a wharf at the Treat Island, ME concrete field exposure site located at the Bay of Fundy. The blocks examined in this paper were demolded at 24 hours and cured for up to 3 days with wet burlap and plastic. The blocks cast as part of Phase I were then cured in the moist room for 28 days, whereas the remainder of the blocks cured in the moist room for 90 days or more. ${ }^{37}$ The timber wharf at the mid-tide level experiences two wetting and drying cycles daily from the $6 \mathrm{~m}(19.7 \mathrm{ft})$ tide, and approximately 100 freezing-and-thawing cycles annually. After 25 years of exposure, one of the concrete blocks from each set of mixtures made during the first five phases was collected. The concrete blocks had $w / \mathrm{cm}$ ranging from 0.4 to 0.6 , with GGBFS, fly ash, and silica fume contents as shown in Table 1. Lightweight aggregates that were soaked in water for 24 hours prior to mixing were used in the blocks cast in Phases III and VI. Normalweight aggregates were used in the remainder of the blocks tested in this study. The concrete blocks were air entrained with $6 \pm 1 \%$ air. The average absolute error (AAE) and the coefficient of determination $R^{2}$ for the modeled values for each block are also shown in Table 1 . The AAE is calculated using Eq. (12) ${ }^{38}$

$$
\mathrm{AAE}=\frac{\sum(|\hat{y}-y|)}{n}
$$

where $\hat{y}$ is the simulated chloride concentration; $y$ is the measured chloride concentration; and $n$ is the number of data points used in the analysis. The cement and SCM properties are shown in Tables 2 and 3, respectively. ${ }^{37}$ The chloride profile for each of these blocks was measured for comparison to the modeled values. A chloride surface concentration of $0.8 \%$ concrete weight was used to model the chloride loading for the concrete blocks measured. ${ }^{10}$

The service life simulations did a good job of predicting the chloride ingress for ordinary portland cement (OPC) 
Table 3-Chemical and physical properties of supplementary cementitious materials used in study ${ }^{38}$

\begin{tabular}{l|c|c|c|c|c|c|c}
\hline \multicolumn{1}{c|}{ Property } & Phase I & Phase II & Phase II & Phase III & Phase IV & Phase V & Phase VI \\
\hline Material type & Slag & Slag & Fly ash & Slag & Fly ash & Slag & Silica fume \\
\hline $\mathrm{SiO}_{2}, \%$ & 36.84 & 36.84 & 52.68 & 38.78 & 47.72 & 35.5 & 92 \\
\hline $\mathrm{CaO}, \%$ & 36.92 & 36.92 & 1.02 & 37.88 & 1.16 & 39.4 & 0.4 \\
\hline Loss on ignition, \% & 0.23 & 0.23 & 3.45 & - & 3.43 & 0.2 & 3 \\
\hline $\mathrm{Al}_{2} \mathrm{O}_{3}, \%$ & 9.53 & 9.53 & 29.36 & 8.11 & 25.92 & 11.4 & 0.4 \\
\hline $\mathrm{Fe}_{2} \mathrm{O}_{3}, \%$ & 1.11 & 1.11 & 9.14 & 1.02 & 14.01 & 0.5 & 1.5 \\
\hline $\mathrm{SO}_{3}, \%$ & 0.1 & 0.1 & 0.39 & 0.12 & 1 & 0.6 & 0.2 \\
\hline $\mathrm{MgO}_{2} \%$ & 11.07 & 11.07 & 1.35 & 9.49 & 1.6 & 11.9 & 0.4 \\
\hline $\mathrm{Na}_{2} \mathrm{O}, \%$ & 0.28 & 0.28 & 0.32 & 0.49 & 0.5 & 0.16 & 0.2 \\
\hline $\mathrm{K}_{2} \mathrm{O}, \%$ & 0.36 & 0.36 & 2.57 & 0.52 & 3.15 & 0.2 & 1 \\
\hline Alkalies (as Na $2 \mathrm{Oeq}) \%$ & 0.52 & 0.52 & 2.02 & 0.83 & 2.57 & 0.29 & 0.9 \\
\hline $\mathrm{Blaine}, \mathrm{m}^{2} / \mathrm{kg}$ & 466 & 466 & 295 & 429 & 392 & - & - \\
\hline
\end{tabular}

concrete, especially at $0.4 w / \mathrm{cm}$. Figures 6(a), (b), and (c) show the measured and modeled chloride concentration with depth for the concrete mixtures without SCMs at 0.4, 0.5, and $0.6 \mathrm{w} / \mathrm{cm}$, respectively. As seen in Fig. 6(a) through (c), there is a wide scatter in the chloride content with depth for different concrete blocks containing different cements. The model did well at predicting the shape of the chloride profile with depth at a $w / \mathrm{cm}$ of 0.4 , but not at the $0.6 \mathrm{w} / \mathrm{cm}$. There are several possible explanations for this discrepancy. First, the blocks with the higher $w / \mathrm{cm}$ also had lower cement contents and, consequently, reduced chloride binding. The concrete at the higher $w / \mathrm{cm}$ also showed a considerable amount of scaling from the combined salt crystallization and freezingand-thawing damage, as shown in Fig. 7. This damage lowered the measured chloride content at the surface because the paste content, which is where the chlorides are found, was lower there. The worn surface also made it easier for chlorides to penetrate deeper into the concrete through microcracks and missing paste, accounting for the much flatter measured chloride distribution than what was predicted.

The decrease in the apparent chloride diffusivity for concrete containing GGBFS was well-simulated for the concrete with a $0.4 \mathrm{w} / \mathrm{cm}$, evidenced by an average $R^{2}$ value of 0.9 and an average AAE of $0.05 \%$, and shown in Fig. 8(a) and (b). These figures also show that the concrete containing lightweight aggregates had similar chloride ingress profiles to the concrete mixtures with normalweight aggregates. The concrete made with lightweight aggregates did just as well as the concrete made with normalweight aggregate at a $w / \mathrm{cm}$ of 0.4 and 0.5 . At a $w / \mathrm{cm}$ of 0.6 , however, the concrete made with lightweight aggregate crumbled. The concrete blocks made with GGBFS at a $0.6 \mathrm{w} / \mathrm{cm}$ also showed considerable scaling and mass loss from the freezing-and-thawing cycles, and is shown for Concrete Block C11 in Fig. 7. This scaling lowered the concrete chloride concentration at the surface, similar to that seen for the concrete without SCMs, confirming the $w / \mathrm{cm}$ requirements for concrete exposed to freezing and thawing in ACI $318 .{ }^{39}$ The poor durability of the concrete blocks containing lightweight aggregate and GGBFS at a $0.6 \mathrm{w} / \mathrm{cm}$ demonstrates that using an appropriate $w / \mathrm{cm}$ in concrete is one of the most important parameters in producing durable concrete. The average $R^{2}$ value for concrete made with GGBFS and a $0.6 \mathrm{w} / \mathrm{cm}$ was 0.63 , with an AAE of 0.12. The simulations of concrete containing fly ash performed similarly to the concrete containing GGBFS, and are shown for the concrete at a $w / \mathrm{cm}$ of 0.4 in Fig. 9. The
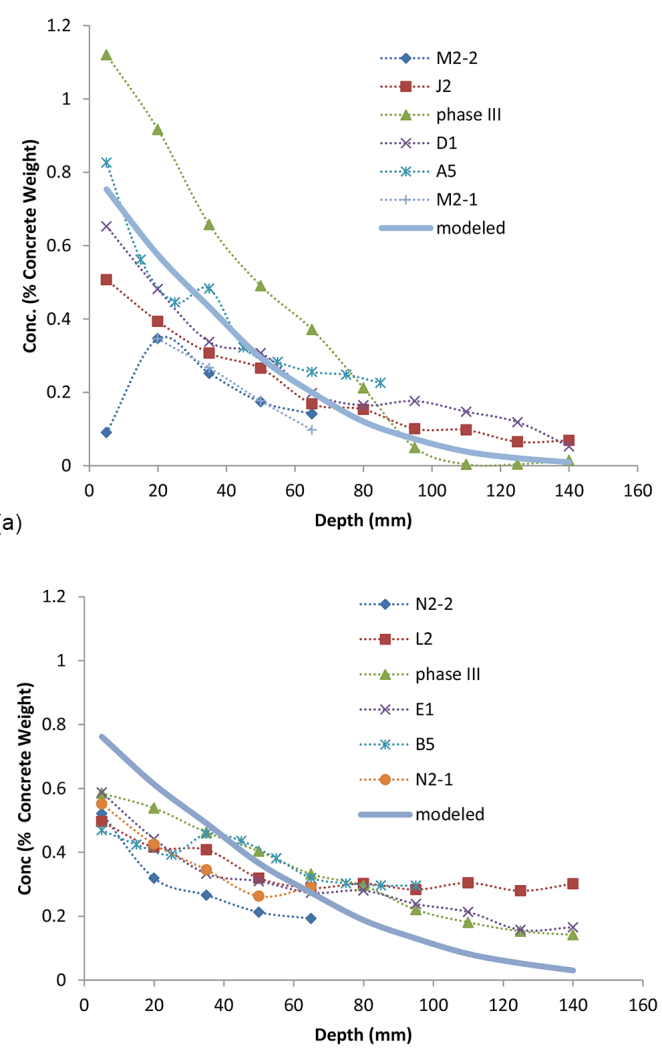

(b)

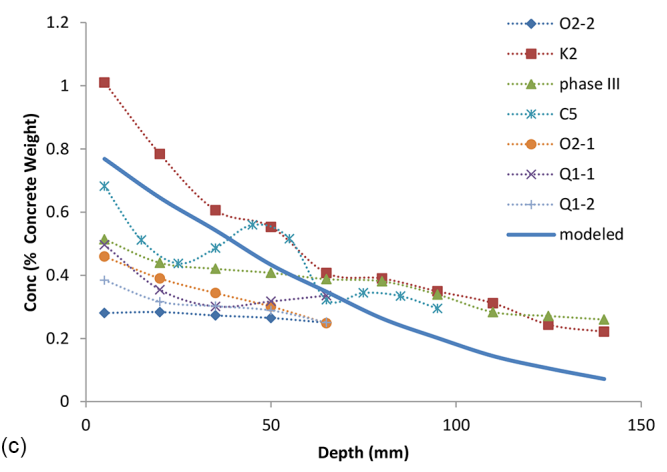

Fig. 6-Measured and modeled concrete chloride concentration with depth for concrete blocks after 25 years made with $100 \%$ portland cement and: (a) $0.4 \mathrm{w} / \mathrm{cm} ;(b) 0.5 \mathrm{w} / \mathrm{cm}$; and (c) $0.6 \mathrm{w} / \mathrm{cm}$. (Note: $1 \mathrm{~mm}=0.0394 \mathrm{in}$.) 


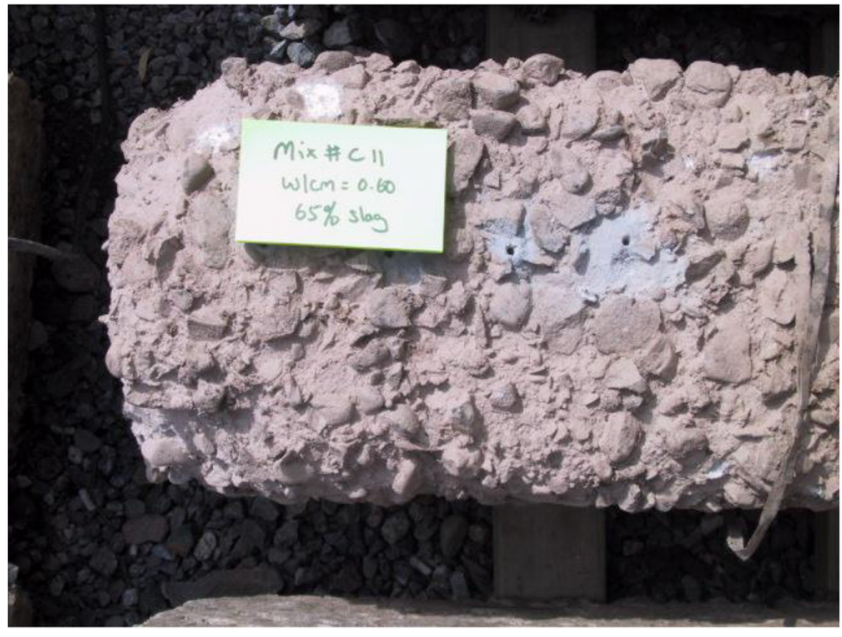

Fig. 7-Scaling on Concrete Block C11 with $0.6 \mathrm{w} / \mathrm{cm}$ and $65 \%$ GGBFS.
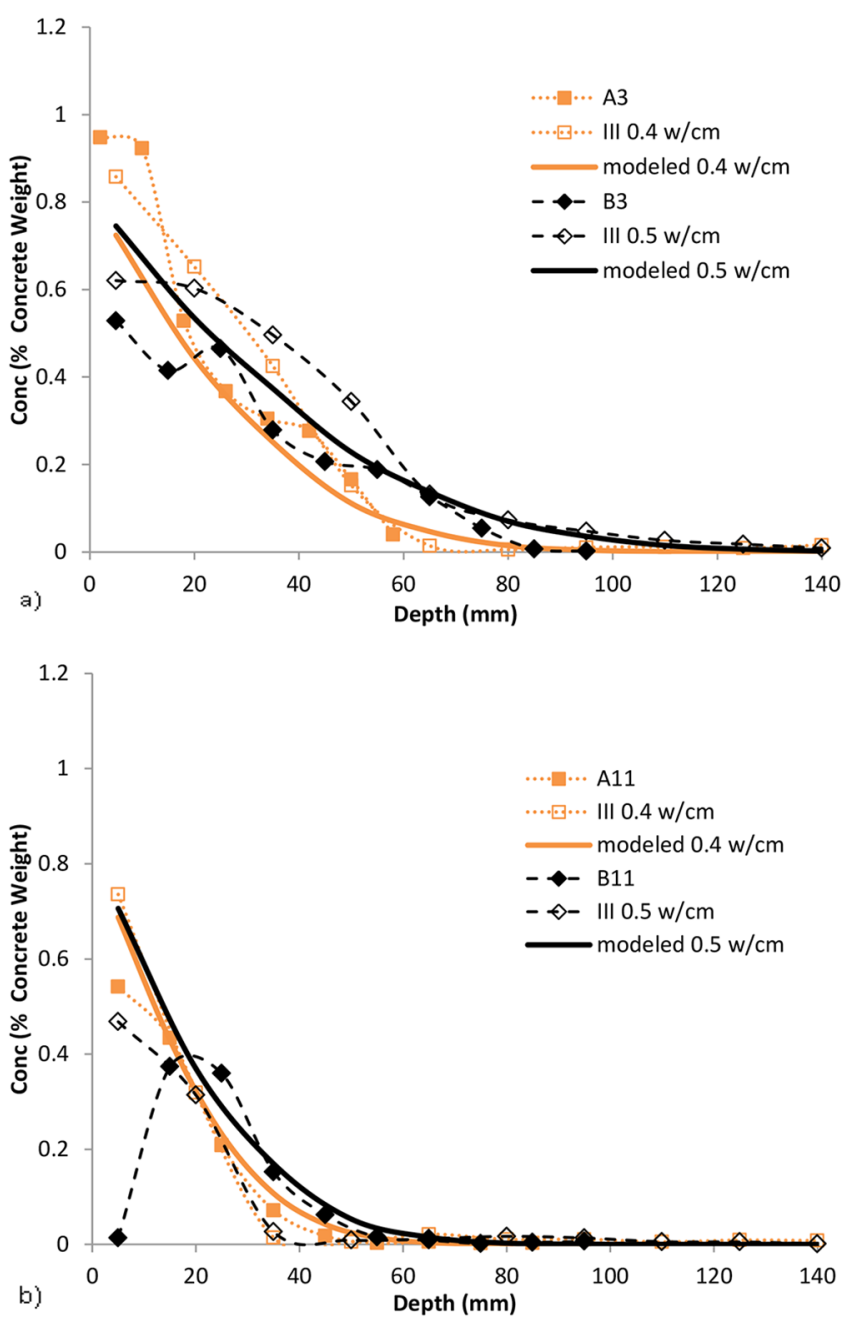

Fig. 8-Chloride concentration with depth for concrete blocks after 25 years containing slag at: (a) 25\%; and (b) $65 \%$. (Note: $1 \mathrm{~mm}=0.0394 \mathrm{in}$.)

concrete blocks made as part of Phase V (B) showed significant scaling and consequently lower salt concentrations close to the surface, likely caused by the high $w / \mathrm{cm}$. The salt concentration in the block containing $20 \%$ silica fume was much lower than predicted by the simulation, as shown in

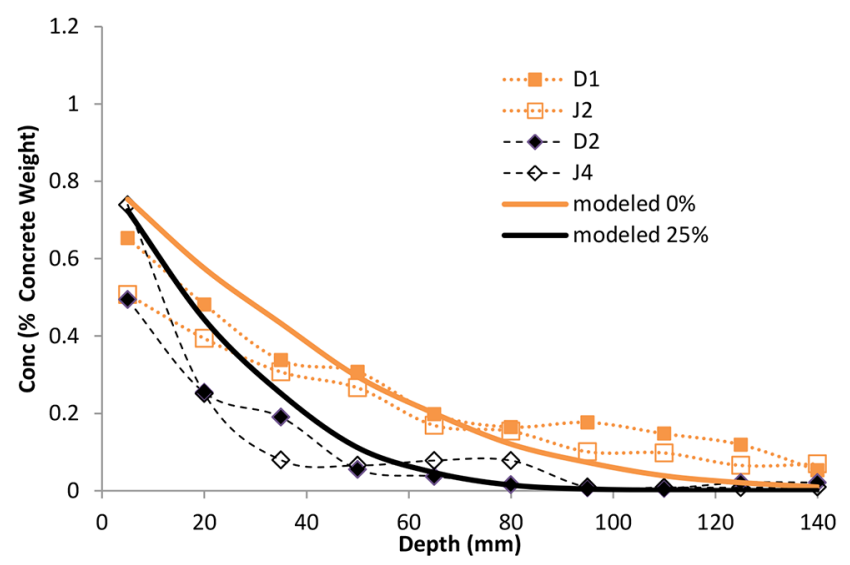

Fig. 9-Effect of fly ash on chloride ingress in concrete blocks after 25 years at $0.4 \mathrm{w} / \mathrm{cm}$. (Note: $1 \mathrm{~mm}=0.0394 \mathrm{in}$.)

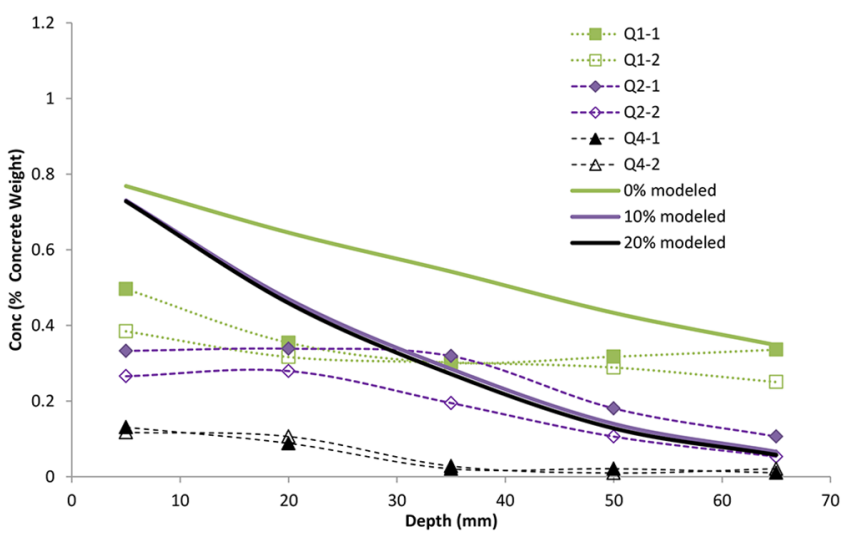

Fig. 10-Effect of silica fume on chloride ingress for concrete blocks after 25 years at $\mathrm{w} / \mathrm{cm}$ of 0.6. (Note: $1 \mathrm{~mm}=0.0394 \mathrm{in}$.)

Fig. 10. The data used to develop the equation for the change in the concrete diffusivity only contained up to $12 \%$ cement replacement by silica fume, giving possible errors in the model extrapolation. This should not cause many problems for most construction because silica fume is rarely used to replace more than $12 \%$ portland cement, and slag cement is rarely used to replace more than $70 \%$ portland cement.

\section{CONCLUSIONS}

A model for predicting the chloride ingress in marine conditions was presented based on concrete apparent chloride diffusion testing from the literature and new testing performed. Fifty-four concrete blocks were cast at a $w / \mathrm{cm}$ varying from 0.4 to 0.6 and containing fly ash content up to 25 , GGBFS up to $80 \%$, and silica fume content up to $20 \%$ and exposed to aggressive marine conditions for 25 years. The chloride profiles in these blocks were measured by profile grinding and compared to the values predicted using the concrete apparent chloride diffusion model presented in this paper. The predicted chloride profiles compared very well. The model did a very good job of predicting the chloride ingress for the concrete mixtures at $0.4 \mathrm{w} / \mathrm{cm}$, with an average $R^{2}$ value of 0.79 and an AAE of 0.08 . The model fit was not as good for the $0.6 \mathrm{w} / \mathrm{cm}$ concrete with an average $R^{2}$ value of 0.51 and an average AAE of 0.17 . The values measured at the higher $w / \mathrm{cm}$ tended to have lower chloride 
contents at the surface than predicted and flatter ingress profiles compared to the predicted profiles because of surface scaling. The surface scaling seen with the high-w/cm concretes also validates the $w / \mathrm{cm}$ limits for concrete exposed to deicer salts and freezing-and-thawing cycles found in modern building codes.

\section{ACKNOWLEDGMENTS}

The support of CANMET and the U.S. Army Corps of Engineers in providing access to the Treat Island, ME, field site and the concrete blocks is gratefully acknowledged.

\section{REFERENCES}

1. Mindess, S.; Young, J. F.; and Darwin, D., Concrete, second edition, Prentice Hall, Upper Saddle River, NJ, 2003, 644 pp.

2. Pillai, R. G., and Trejo, D., "Surface Condition Effects on Critical Chloride Threshold of Steel Reinforcement," ACI Materials Journal, V. 102, No. 2, Mar.-Apr. 2005, pp. 103-109.

3. Claisse, P., "Transport Properties of Concrete," Concrete International, V. 27, No. 1, Jan. 2005, pp. 43-48

4. ACI Committee 201, "Guide to Durable Concrete (ACI 201.2R-08)," American Concrete Institute, Farmington Hills, MI, 2008, 49 pp.

5. Kosmatka, S. H.; Kerkhoff, B.; and Panarese, W. C., Design and Control of Concrete Mixtures, 14th edition, Portland Cement Association, Skokie, IL, 2008, 358 pp.

6. Thomas, M. D. A., and Bamforth, P. B., "Modelling Chloride Diffusion in Concrete: Effect of Fly Ash and Slag," Cement and Concrete Research, V. 29, 1999, pp. 487-495.

7. Neville, A. M., Properties of Concrete, fourth edition, Pearson Education Limited, Harlow, Essex, England, 2008, 844 pp.

8. ASTM C1556-04, "Standard Test Method for Determining the Apparent Chloride Diffusion Coefficient of Cementitious Mixtures by Bulk Diffusion," ASTM International, West Conshohocken, PA, 2004, 7 pp.

9. Stanish, K., and Thomas, M., "The Use of Bulk Diffusion Tests to Establish Time-Dependent Concrete Chloride Diffusion Coefficients," Cement and Concrete Research, V. 33, 2003, pp. 55-62.

10. Ehlen, M. A.; Thomas, M. D. A.; and Bentz, E. C., "Life-365 Service Life Prediction Model ${ }^{\mathrm{TM}}$ Version 2.0," Life-365 Consortium II, User Manual, 2009

11. Thomas, M. D. A.; Scott, A.; Bremner, T.; Bilodeau, A.; and Day, D., "Performance of Slag Concrete in Marine Environment," ACI Materials Journal, V. 105, No. 6, Nov.-Dec. 2008, pp. 628-634.

12. Bamforth, P. B., "Spreadsheet Model for Reinforcement Corrosion in Structures Exposed to Chlorides," Concrete Under Severe Conditions 2, O. E. Gjørv, K. Sakai, and N. Banthia, eds., E\&FN Spon, London, UK, 1998, pp. 64-75.

13. Maage, M.; Helland, S.; and Carlsen, J. E., "Practical Non-steady State Chloride Transport as a Part of a Model for Predicting the Initiation Period," Chloride Penetration into Concrete, L. O. Nilsson and J. Ollivier, eds., 1995, pp. 398-406.

14. Mangat, P. S., and Molloy, B. T., "Prediction of Long Term Chloride Concentrations in Concrete," Materials and Structures, V. 27, 1994, pp. 338-346.

15. Tang, L., and Nilsson, L.-O., "Chloride Diffusivity in High Strength Concrete at Different Ages," Nordic Concrete Research, V. 11, No. 1, 1992, pp. 162-171.

16. Thomas, M. D. A., and Bamforth, P. B., "Modelling Chloride Diffusion in Concrete; Effect of Fly Ash and Slag," Cement and Concrete Research, V. 29, No. 4, 1999, pp. 487-495.

17. Frederiksen, J. M.; Sorensen, H. E.; Andersen, A.; and Klinghoffer, O., "The Effect of the w/c Ratio on Chloride Transport into Concrete-Immersion, Migration and Resistivity Tests," HETEK Report No. 54, 1997.

18. Tang, L., and Sorenson, H. E., "Evaluation of the Rapid Test Methods for Measuring the Chloride Diffusion Coefficients of Concrete," SP Report 1998:42, Nordtest Project No. 1388-98, 1998.

19. Stanish, K., "Predicting the Diffusion Coefficient of Concrete from Mix Parameters," University of Toronto Report, University of Toronto, ON, Canada, 2000.

20. Steen, P. E. "Chloride Penetration in Marine Environment Part 2: Results from Field Test on Coastal Bridges in Norway," Proceedings of the
Nordic Seminar in Lund: Corrosion of Reinforcement: Field and Laboratory Studies for Modeling and Service Life, 1995.

21. Sandberg, P.; Pettersson, K.; and Jorgensen, O., "Field Studies of Chloride Transport into High Performance Concrete," Proceedings of the Third CANMET/ACI International Conference on the Performance of Concrete in a Marine Environment, SP-163, V. M. Malhotra, ed., American Concrete Institute, Farmington Hills, MI, 1996, pp. 233-254.

22. Sandberg, P., and Tang, L., "A Field Study of the Penetration of Chlorides and Other Ions into a High Quality Concrete Marine Bridge Column," Proceedings of the Third CANMET/ACI International Conference on Durability of Concrete, SP-145, V. M. Malhotra, ed., American Concrete Institute, Farmington Hills, MI, 1994, pp. 557-571.

23. Rodriguez, O. G., "Influence of Cracks on Chloride Ingress into Concrete," MASc thesis, University of Toronto, Toronto, ON, Canada, 2001.

24. Smith, D., "The Development of a Rapid Test for Determining the Transport Properties of Concrete," MScE thesis, University of New Brunswick, Fredericton, NB, Canada, 2006.

25. Obla, K. H.; Hill, R. L.; Thomas, M. D. A.; Shashiprakash, S. G.; and Perebatova, O., "Properties of Concrete Containing Ultra-Fine Fly Ash," ACI Materials Journal, V. 100, No. 5, Sept.-Oct. 2003, pp. 426-433.

26. Sherman, M. R.; McDonald, D. B.; and Pfeifer, D. W., "Durability Aspects of Precast, Prestressed Concrete Part 2: Chloride Permeability Study," PCI Journal, V. 41, No. 4, 1996, pp. 76-95.

27. Pun, P., "Influence of Silica Fume on Chloride Resistance of Concrete," MASc thesis, University of Toronto, Toronto, ON, Canada, 1997

28. Titherington, M. P., "The Influence of Steam Curing on the Chloride Resistance of High Performance Concrete," MASc thesis, University of Toronto, Toronto, ON, Canada, 1998.

29. Sandberg, P., "Recent Studies of Chloride Ingress in Uncracked Marine Concrete at Various Exposure Times and Elevations," Report TVBM-3080, Division of Building Materials, Lund University Institute of Technology, Lund, Sweden, 1998.

30. Gjørv, O. E.; Tan, K.; and Zhang, M.-H., "Diffusivity of Chlorides from Seawater into High-Strength Lightweight Concrete," ACI Materials Journal, V. 91, No. 5, Sept.-Oct. 1994, pp. 447-452.

31. Boddy, A.; Hooton, R. D.; and Gruber, K. A., "Long-Term Testing of the Chloride-Penetration Resistance of Concrete Containing High-Reactivity Metakaolin," Cement and Concrete Research, V. 31, No. 5, 2001, pp. 759-765.

32. Bamforth, P. B., "Spreadsheet Model for Reinforcement Corrosion in Structures Exposed to Chlorides," Concrete Under Severe Conditions 2, O. E. Gjørv, K. Sakai, and N. Banthia, eds., E\&FN Spon, London, UK, 1998, pp. 64-75.

33. Incropera, F. P., and DeWitt, D. P., Fundamentals of Heat and Mass Transfer, fifth edition, John Wiley \& Sons, Inc., New York, 2002, 944 pp.

34. Tuutti, K., "Corrosion of Steel in Concrete," Report No. 4-82, Swedish Cement and Concrete Research Institute, Stockholm, Sweden, 1982.

35. Glass, G. K., and Buenfeld, N. R., "Chloride Threshold Levels for Corrosion Induced Deterioration of Steel in Concrete," Chloride Penetration into Concrete, Saint-Rémy-lès-Chevreuse, France, 1995, pp. 429-440.

36. Malhotra, V. M., and Bremner, T. W., "Performance of Concrete at Treat Island, U.S.A.: CANMET Investigations," Proceedings of the Third CANMET/ACI International Conference on the Performance of Concrete in a Marine Environment, SP-163, V. M. Malhotra, ed., American Concrete Institute, Farmington Hills, MI, 1996, pp. 1-52.

37. Malhotra, V. M.; Carette, G. G.; and Bremner, T. W., "Current Status of CANMET's Studies on the Durability of Concrete Containing Supplementary Cementing Materials in Marine Environment," Concrete in a Marine Environment, SP-109, V. M. Malhotra, ed., American Concrete Institute, Farmington Hills, MI, 1988, pp. 31-72.

38. Carino, N. J., and Tank, R. C., "Maturity Functions for Concretes Made with Various Cements and Admixtures," ACI Materials Journal, V. 89, No. 2, Mar.-Apr. 1992, pp. 188-196.

39. ACI Committee 318, "Building Code Requirements for Structural Concrete (ACI 318-08) and Commentary," American Concrete Institute, Farmington Hills, MI, 2008, 473 pp. 
